\title{
Philosophiques
}

\section{Index du volume 33 (2006)}

Volume 33, numéro 2, automne 2006

URI : https://id.erudit.org/iderudit/013906ar

DOI : https://doi.org/10.7202/013906ar

Aller au sommaire du numéro

Éditeur(s)

Société de philosophie du Québec

ISSN

0316-2923 (imprimé)

1492-1391 (numérique)

Découvrir la revue

Citer ce document

(2006). Index du volume 33 (2006). Philosophiques, 33(2), 553-554.

https://doi.org/10.7202/013906ar

Ce document est protégé par la loi sur le droit d'auteur. L'utilisation des services d'Érudit (y compris la reproduction) est assujettie à sa politique d'utilisation que vous pouvez consulter en ligne.

https://apropos.erudit.org/fr/usagers/politique-dutilisation/
Cet article est diffusé et préservé par Érudit.

Érudit est un consortium interuniversitaire sans but lucratif composé de l'Université de Montréal, l'Université Laval et l'Université du Québec à Montréal. Il a pour mission la promotion et la valorisation de la recherche. https://www.erudit.org/fr/ 


\section{Index du volume 33 (2006)}

\section{Articles}

Amselek, Paul, Les fonctions normatives ou catégories modales

Charland, Louis C., La psychopathologie et le statut d'espèce naturelle de l'émotion

Dumouchel, Paul, Qu'est-ce qu'une maladie? Pinel, aliéniste et nosographe

Faucher, Luc, Poirier, Pierre et Lachapelle, Jean, La théorie des systèmes développementaux et la construction sociale des maladies mentales

FAucher, Luc, Présentation

GANDON, SÉBASTIEN, Grandeurs, vecteurs et relations chez Russell (1897-1903) 333

Gerrans, Philip, La lecture de pensée pour débutants

Guibert Lafaye, Caroline, Le critère d'absence d'envie dans les théories contemporaines de la justice

LEROUX, JeAn, Langage et pensée chez W. von Humboldt

Macdonald, IAIN, L'art in extremis : le monochrome chez Theodor W. Adorno et Yves Klein

MestiRi, Soumaya, Peut-on se passer de la position originelle?

Perring, Christian, Conceptualiser les troubles mentaux chez les enfants et les adolescents

Poland, JeFrerey, Étapes vers un monde sans schizophrénie

SOLER, LÉNA, Contingence ou inévitabilité des résultats de notre science ?

Stevens, G. Lynn et Graham George, Reconcevoir le délire

VANDERVEKEN, DANIEL, In memoriam Raymond Klibansky. Hommage à un grand maître

Vignemont, FrédÉRIQUE DE, L'hystérie : ne plus vouloir pouvoir, ne plus pouvoir vouloir

WaKefield, Jerome, Fait et valeur dans le concept de trouble mental: le trouble en tant que fonction préjudiciable

ZACHAR, PETER, Les troubles psychiatriques et le modèle des espèces pratiques

\section{Disputationes}

Davis, Steven, Literal Meaning de F. Recanati

Gillon, Brandon S., Du sens littéral

Maclure, Jocelyn, De l'herméneutique de la modernité à l'éthique normative

McCarthy, Thomas, Imaginaires sociaux et modernités multiples

Patton, Paul, L'identité des imaginaires sociaux et la nature des droits

Recanati, François, Précis de Literal Meaning

RECANATI, FrançOIs, Réponses à mes critiques

SEymour, Michel, Le contextualisme sémantique en perspective 


\section{Philosophiques / Automne 2006}

TAYlor, Charles, Précis de Modern Social Imaginaries $\quad 477$

TAYlor, Charles, Réponses à mes critiques $\quad 507$

\section{Études critiques}

Harris, John, On Cloning (Mark Hunyadi) 289

OGIEn, Ruwen, La panique morale (Nicolas Tavaglione) 513

\section{Comptes rendus}

Bouchard, Yves, Le holisme épistémologique de Kant (Sophie Grapotte) 302

Faye, Emmanuel, Heidegger, L'introduction du nazisme dans la philosophie. Autour des séminaires inédits de 1933-1935 (Luc Vigneault)

FISETTE, DenIs, Husserl's Logical Investigations reconsidered (Pierre-Jean Renaudie)

Fournel , Jean-Louis, Jean Claude Zancarini, La politique de l'expérience; Marie Gaille-Nikodimov, Conflit civil et liberté. La politique machiavélienne entre histoire et médecin

MaCHIAVEL, Discours sur la première décade de Tite-Live (Christian Nadeau)

Nikseresht, Iraj, Physique quantique. Origines, interprétations et critiques (Yvon Gauthier)

Piché, DAvid, La querelle des universaux à la Faculté des arts de Paris entre 1230 et 1260 (Aurélien Robert)

Proust, Joëlle, La nature de la volonté (Benoit Dubreuil)

Rosenkranz, Karl, Vie de Hegel suivi de Apologie de Hegel contre le docteur Haym (Éric Guay)

Russell, Bertrand, L'art de philosopher (Isabelle Martineau)

Russell, Bertrand, L'autorité et l'individu (Isabelle Martineau)

Schnieder, Benjamin, Substanz und Adhärenz. Bolzanos Ontologie des Wirklichen (Paola Cantu)

Tavaglione, Nicolas, Le dilemme du soldat. Guerre juste et prohibition du meurtre (Karine Wurtz) 